Article

\title{
Evidence of Decoupling Protein Structure from Spidroin Expression in Spider Dragline Silks
}

\author{
Sean J. Blamires ${ }^{1, *}$, Michael M. Kasumovic ${ }^{1}$, I-Min Tso ${ }^{2}$, Penny J. Martens ${ }^{3}$, James M. Hook ${ }^{4}$ \\ and Aditya Rawal ${ }^{4}$ \\ 1 Evolution \& Ecology Research Centre, School of Biological, Earth \& Environmental Sciences, \\ University of New South Wales, Sydney 2052, Australia; m.kasumovic@unsw.edu.au \\ 2 Department of Life Science, Tunghai University, Taichung 40704, Taiwan; spider@thu.edu.tw \\ 3 Graduate School of Biomedical Engineering, University of New South Wales, Sydney 2052, Australia; \\ p.martens@unsw.edu.au \\ 4 NMR Facility, Mark Wainwright Analytical Centre, University of New South Wales, Sydney 2052, Australia; \\ j.hook@unsw.edu.au (J.M.H.); a.rawal@unsw.edu.au (A.R.) \\ * Correspondence: s.blamires@unsw.edu.au; Tel.: +61-2-9385-1261 \\ Academic Editor: John G. Hardy \\ Received: 30 June 2016; Accepted: 1 August 2016; Published: 9 August 2016
}

\begin{abstract}
The exceptional strength and extensibility of spider dragline silk have been thought to be facilitated by two spidroins, major ampullate spidroin 1 (MaSp1) and major ampullate spidroin 2 (MaSp2), under the assumption that protein secondary structures are coupled with the expressed spidroins. We tested this assumption for the dragline silk of three co-existing Australian spiders, Argiope keyserlingi, Latrodectus hasselti and Nephila plumipes. We found that silk amino acid compositions did not differ among spiders collected in May. We extended these analyses temporally and found the amino acid compositions of $A$. keyserlingi silks to differ when collected in May compared to November, while those of L. hasselti did not. To ascertain whether their secondary structures were decoupled from spidroin expression, we performed solid-state nuclear magnetic resonance spectroscopy (NMR) analysis on the silks of all spiders collected in May. We found the distribution of alanine toward $\beta$-sheet and 3,10 helix/random coil conformations differed between species, as did their relative crystallinities, with $A$. keyserlingi having the greatest 3,10 helix/random coil composition and $N$. plumipes the greatest crystallinity. The protein secondary structures correlated with the mechanical properties for each of the silks better than the amino acid compositions. Our findings suggested that a differential distribution of alanine during spinning could decouple secondary structures from spidroin expression ensuring that silks of desirable mechanical properties are consistently produced. Alternative explanations include the possibility that other spidroins were incorporated into some silks.
\end{abstract}

Keywords: amino acids; high performance liquid chromatography; mechanical properties; orb weaving spiders; protein secondary structures; silk spinning; solid-state nuclear magnetic resonance spectroscopy

\section{Introduction}

The exceptional strength, extensibility and toughness of spider dragline, or major ampullate (MA), silk make it a desirable material for multiple industrial uses [1]. Dragline silk is traditionally thought to be comprised of two proteins (spidroins), conventionally called major ampullate spidroin 1 (MaSp1) and major ampullate spidroin 2 (MaSp2). Generally, the structures of these proteins are considered critical to the mechanical function of dragline silk.

Techniques that can probe protein structures include small and wide angle X-ray scattering, Fourier Transform Infrared Spectroscopy (FTIR) and various forms of nuclear magnetic resonance 
(NMR) spectroscopy [2-7]. Small and wide angle X-ray scattering are used explicitly for examining the size, density and orientation of crystalline and non-crystalline structures [5]. Since NMR detects magnetically active isotopes such as ${ }^{1} \mathrm{H},{ }^{13} \mathrm{C}$ and ${ }^{15} \mathrm{~N}$, it is used to identify the molecular orientations and bonding arrangements within protein secondary structures [8]. As such, solid state nuclear magnetic resonance (ssNMR) spectroscopy has been effectively used to assess the relationship between spider dragline silk amino acid compositions and the formation of protein secondary structures, as well as protein chain dynamics [7-15].

ssNMR has shown MaSp1 to consist of multiple $(\mathrm{GA})_{\mathrm{n}},(\mathrm{GGX})_{\mathrm{n}}$ and $(\mathrm{A})_{\mathrm{n}}$ repeated amino acid sequences $(G=$ glycine, $A=$ alanine and $X=$ other amino acids) and it is assumed that these sequences promote the formation of crystalline $\beta$-sheet structures in assembled fibers $[3,9,16]$. MaSp2, on the other hand, consists of multiple $(\mathrm{GPGXX})_{n}$ repeated sequences $(\mathrm{P}=$ proline $)[10,17]$. This sequence is currently assumed to self-assemble into $\beta$-spirals and type-II $\beta$-turns in the silk fibers $[6,18]$. Since MaSp2 contains (GPGXX) $)_{n}$ repeated sequences, the proline composition of dragline silk has been used as an indicator of the presence of MaSp2. Thus, the combined expression of MaSp1 and MaSp2 are assumed to be coupled to the presence of various quantities of crystalline $\beta$-sheets, $\beta$-spirals and type-II $\beta$-turns, which are in turn thought to provide dragline silk with its great strength and extensibility [1].

The positioning of the alanine residues is an important indicator of dragline silk structure that is detectable using ssNMR [13,19-21]. Generally, the majority $(>80 \%)$ of the alanine in MaSp1 resides in $\beta$-sheets, predominantly as $(\mathrm{A})_{\mathrm{n}}$ repeated sequences $[13,19,22,23]$. The rest of the MaSp1 alanine lies in $\alpha$-helices, 3,10helices and type-II $\beta$-turns [23]. The distribution of alanine in MaSp2 varies substantially among silks from different spider species $[13,21-23]$. Since the $\mathrm{C}=\mathrm{O}$ segments bond weakly with adjacent amine segments [24], alanine is mobile during spinning and this mobility is identifiable using ssNMR techniques [19]. Hence the repositioning of alanine within the spidroins might be a detectable mechanism influencing protein secondary structures within dragline silk fibers.

Glycine residues are, likewise, important identifiers of dragline silk structure when using ssNMR. In MaSp1 glycine primarily forms either $(G A)_{n}$, repeating sequences within $\beta$-sheets or $(G G X)_{n}$ repeating sequences within GlyII-helices [25]. Glycine may be mobile during spinning, albeit to a lesser extent than alanine, so variability in glycine distribution between individual dragline silks might also be expected. Proline is found within the (GPGXX) $n$ repeating sequences of MaSp2 and is identified using ssNMR by its tendency to form kinks [18]. It is thought to facilitate extensibility by forming weak hydrogen bonding between the structural components that enable the chains to freely slide past each other [26-29].

ssNMR studies of dragline silk have to date mostly focused on elucidating the amino acid compositions, secondary structures, and molecular dynamics of the spidroins from a few model species, such as Nephila clavipes, Latrodectus hesperus and Argiope aurantia [17,23,25,30]. One study [13] used ssNMR to compare the structures and properties of dragline silks from a range of species from four different spider genera: Araneus, Argiope, Nephila and Latrodectus. Among these genera Araneus and Argiope had dragline silks high in MaSp2 compositions and proline molar compositions of $\sim 11 \%-14 \%$, while Nephila and Latrodectus were low in MaSp2 and proline compositions of only $~ 1 \%-2 \%$ [13].

Studies comparing amino acid compositions in the dragline silks of different species $[16,27,31-33]$ have revealed similar dichotomies in silks produced among different spiders, i.e., spiders seem to produce silks that are either high in MaSp2 or relatively devoid of MaSp2. There, however, does not seem to be any phylogenetic relationship between the spiders expressing silks that are relatively high or low in MaSp2 [32,33]. An explanatory hypothesis for the apparent dichotomy in dragline silk spidroin expression among spiders is that factors such as ecological circumstances, or spider body size, condition, or aging affect spidroin expression. For instance, MaSp2 expression may be down-regulated when a spider is starved or deprived of nutrients [31,34,35]. The finding that silk amino acid composition can differ in the dragline silks from the same species of spider from different regions [36,37] also supports this prediction. Nevertheless, the mechanical performance of a spider's 
silk may be unaffected by variations in spidroin expression [33,38-40]. Thus, there seem to be several ways by which variations in silk mechanical property can be induced among different spiders without sacrificing functional effectiveness.

As silk flows through the major ampullate gland as a crystalline liquid the actions of $\mathrm{pH}$ change, salt concentrations and shear forces in the duct effect the formation of the secondary structures [41-45]. Accordingly, a possible reason why the mechanical properties of dragline silk sometimes vary independent of spidroin expression is that the silk spinning processes decouple spidroin expression from secondary structure formation through an "on-the-fly" redistribution of alanine or glycine residues [46]. This explanation nonetheless remains to be empirically tested in different spiders using multiple techniques. We therefore determined herein the spidroin expression, protein secondary structure and mechanical properties of the dragline silks of three co-existing species of spider from Sydney, Australia: Argiope keyserlingi, Nephila plumipes and Latrodectus hasselti using high performance liquid chromatography (HPLC), ssNMR and tensile testing techniques. All of their silks were collected in May 2014. We determined the structural formations induced by the alanine and glycine residues in the silks from the ssNMR measurements. Any incongruencies between amino acid compositions, protein secondary structures and mechanical properties among spiders were construed as indicating that spinning processes decoupled spidroin expression from protein secondary structures and, thus, mechanical properties $[44,45]$. We additionally investigated temporal variations in spidroin expression by performing further HPLC analyses on Argiope keyserlingi and Latrodectus hasselti silks collected in November. We regarded any similarities in amino acid composition between species at any particular time of year or any differences within species at different times of year as indicating that ecological circumstances or demographic factors influenced spidroin expressions.

\section{Results and Discussion}

\subsection{Amino Acid Compositions}

We found that the dragline silk amino acid compositions did not differ between the three species examined in May (MANOVA: Wilk's $\lambda=0.161 ; F=2.387 ; d f=10,16 ; p=0.058$ ) (Table 1a). We then expanded our spidroin expression analysis by comparing the amino acid compositions of Latrodectus hasselti and Argiope keyserlingi silks collected in November and found differences between species (MANOVA: Wilk's $\lambda=0.022 ; F=25.670 ; d f=12,52 ; p<0.001$ ) (Table 1b). Furthermore, the amino acid composition of $A$. keyserlingi dragline silk collected in May differed from that collected in November (MANOVA: Wilk's $\lambda=0.048 ; F=15.99 ; d f=5,4 ; p=0.009$ ), with the silks from spiders collected in November having a greater percentage alanine $(p=0.038)$ and proline $(p<0.001)$ than those collected in May. On the other hand the amino acid composition of $L$. hasselti dragline silk did not differ between May and November (MANOVA: Wilk's $\lambda=0.313 ; F=1.578 ; d f=5,4 ; p=0.302$ ). By comparing the compositions attained here with those derived from Latrodectus hesperus [47] and Argiope bruennichi [48] dragline silk gene sequences (Table 1c), our results suggested that each of the spiders produced dragline silk comprising of primarily MaSp1 in May, while in November A. keyserlingi produced dragline silk that likely comprised of a greater proportion of MaSp2. Thus, we concluded that spidroin expression in the dragline silk of $A$. keyserlingi differs at different times of year, possibly as a result of changing ecological or demographic circumstances.

We found less variability around the mean compositions for silk collected in May than for silks collected in November (see Table 1). Work and Young [49] noted that some segments within individual silk fibers could differ in amino acid composition and suggested that within a single fiber there may be differences in the ratio of MaSp1 and MaSp2. We accounted for such within fiber variability in amino acid composition here by analyzing the amino acid composition of entire dragline threads from each individual of each species. Accordingly, we considered this source of variation as not being responsible for any of the variation in dragline silk amino acid compositions between species or within species at different times of year. The spiders that we used were all found in similar urban habitats in Sydney, 
Australia. L. hasselti, however, was found in more sheltered microhabitats than A. keyserlingi (L. hasselti was mostly found underneath rigid structures, e.g., park benches, whereas $A$. keyserlingi was more frequently found exposed among vegetation). Accordingly, it seems that the amino acid composition of $A$. keyserlingi silk could vary in concordance with relatively small-scale environmental fluctuations.

Another possibility for the fluctuations in amino acid composition in A. keyserlingi silk is that MaSp1 and MaSp2 are not the only spidroins being expressed. Recent proteomic data using mass spectrometry of solubilized dragline silk from L. hesperus followed by in-solution tryptic cleavage supported the presence of another spidroin, AcSp1 (acinform spidroin 1), within the major ampullate gland as well as in dragline silk fibers [50]. The presence of AcSp1 might explain the unusually high serine compositions in the dragline silks of all species, the lower than predicted (based on sequences of $A$. bruennichi dragline silk [48]) glycine compositions in A. keyserlingi's dragline silk in May and November, and the low alanine composition of L. hasselti's dragline silk (compared to that of L. hesperus [47]) in May (see Table 1).

Table 1. Comparisons of: (a) The glutamine, serine, glycine, alanine and proline compositions (means with standard errors in parentheses) of L. hasselti, A. keyserlingi and N. plumpes dragline silks from spiders collected in May; (b) The glutamine, serine, glycine, alanine and proline compositions (means with standard errors in parentheses) of L. hasselti and A. keyserlingi dragline silks from spiders collected in November; (c) Compositions from dragline silk genetic sequences for Latrodectus hesperus (from reference [47]) and Argiope bruennichi [48]; * Indicates a statistically significant difference in composition was found between for silks collected in November compared to silks collected in May.

\begin{tabular}{cccccc}
\hline & \multicolumn{5}{c}{ Amino Acids (Percentage Composition) } \\
\cline { 2 - 6 } & Glutamine & Serine & Glycine & Alanine & Proline \\
\hline $\begin{array}{c}\text { (a) May } \\
\text { Argiope keyserlingi }\end{array}$ & $7.90(0.88)$ & $7.02(0.72)$ & $35.39(1.52)$ & $26.46(1.87)$ & $4.17(0.84)$ \\
Nephila plumipes & $6.39(0.92)$ & $4.77(0.33)$ & $41.09(0.45)$ & $30.23(0.56)$ & $2.71(0.42)$ \\
Latrodectus hasselti & $9.61(0.20)$ & $6.78(0.62)$ & $37.56(1.67)$ & $26.0(1.92)$ & $3.13(0.65)$ \\
\hline (b) November & & & & & \\
Argiope keyserlingi & $8.27(0.84)$ & $7.34(2.29)$ & $34.61(6.77)$ & $19.34(6.76) *$ & $12.53(1.67) *$ \\
Latrodectus hasselti & $8.99(0.38)$ & $7.47(0.46)$ & $32.28(2.75)$ & $29.55(2.92)$ & $2.79(0.65)$ \\
\hline (c) Sequenced compositions & & & & & \\
Latrodectus hesperus MaSp1 & 6.9 & - & 33.5 & 31.1 & 0.4 \\
Latrodectus hesperus MaSp2 & 11.3 & - & 42.3 & 32.7 & 8.6 \\
Argiope bruennichi MaSp1 & 4.38 & 5.67 & 45.05 & 30.61 & 0 \\
Argiope bruennichi MaSp2 & 14.50 & 3.04 & 38.47 & 22.51 & 12.48 \\
\hline
\end{tabular}

We found a seasonal difference in spidroin expression in A. keyserlingi dragline silk but an absence of any change in the composition in L. hasselti dragline silk, which is consistent with studies showing that amino acid compositions in spider dragline silks that are relatively low in MaSp2 vary less extensively across environments than those high in MaSp2 [31,32,35]. We controlled for diet and nutritional effects on spidroin expression here by pre-feeding the spiders a standardized solution so recent diet did not affect dragline spidroin expression in any species at any time. A likely explanation for the seasonal variation in the amino acid composition of $A$. keyserlingi dragline silk is that MaSp2 was considerably down-regulated in May because it is synthesized at a considerable metabolic expense [34,35]. MaSp1 synthesis, on the other hand, is significantly less expensive, so is largely unregulated [31]. The three species examined here have different seasonal activity patterns, so their MaSp2 expression is likely to be regulated differently. Studies incorporating more environmental measurements across seasons and habitats are nonetheless required to better elucidate the particular circumstances that induce changes in dragline silk spidroin expression among co-existing web building spiders. 


\subsection{Solid-State Nuclear Magnetic Resonance Spectroscopy}

For ${ }^{13} \mathrm{C}$ cross -polarization magic-angle spin (CPMAS) NMR experiments the ${ }^{13} \mathrm{C}$ signal of a given functional group is dependent on the ${ }^{1} \mathrm{H}-{ }^{13} \mathrm{C}$ cross-polarization dynamics. The ${ }^{13} \mathrm{C}$ signal intensity in a CPMAS spectrum will depend upon: (a) the protonation state of the carbon; (b) the local molecular mobility of the ${ }^{13} \mathrm{C}$ site; and (c) the concentration of the ${ }^{13} \mathrm{C}$ species in the material. Since the signals for the alanine and glycine functional groups were constant among the three spider's silk samples here and we compared the same kind of ${ }^{13} \mathrm{C}$ species, i.e., the methyl species, our spectra depended only on local molecular motions and concentration. We had similar materials in all samples, i.e., large spidroins, so any difference in the local molecular motions will be a function of the degree of hydration. Although we were careful not to expose the silks to the atmosphere, we took the additional precaution of measuring the ${ }^{1} \mathrm{H}$ spectra of the different silks. While the signals from the water peak (5-10 ppm [21]) indicated that some water binding was present, the signals were generally broad and the peaks relatively small (see Figure S1) compared to what would be expected if the material had absorbed a large amount of water, for instance during supercontraction [11,19]. Thus, we were sure that humidity did not strongly influence our spectra attained. The tall, narrow peaks associated with each of the curves of Figure S1 were all found around 0 ppm so attributed to large amino acids or molecules associated with the silk's skin [6,8]. Subsequently, we were confident that we attained highly reliable ${ }^{13} \mathrm{C}$ CPMAS NMR spectra, enabling us to compare the relative intensities of the ${ }^{13} \mathrm{C}$ signals among the different dragline silks and to compare secondary structures between individuals and species.

The ${ }^{13} \mathrm{C}$ cross-polarization magic-angle spectra for the three species' silks are presented in Figure 1. All spectra were scaled to equal the intensity of the $\mathrm{C}=\mathrm{O}$ peak. An additional plot of the variation of the spider silk among individuals of each species is presented in the Supplementary Materials (Figure S2). The peaks were assigned in accordance with Creager et al. [13] to enable estimation of the different residues and domains. The most striking difference that our ssNMR analyses found between the spidroin structures of the three species silks collected in May was the relative intensities of the $\mathrm{C}_{\beta}$ signal on alanine in $\beta$-sheets (peaking at $21.5 \mathrm{ppm}$ ) versus 3,10 helices/random coil (peaking at $17.5 \mathrm{ppm}$ ). We found that $A$. keyserlingi silk collected in May had the lowest $\beta$-sheet signal intensities relative to that of 3,10 helices/random coil, while the N. plumipes and L. hasselti silk collected in May had much stronger $\beta$-sheet signal intensities relative to 3,10 helices/random coil (see Figure 1). Assuming similar cross polarization of the methyl sites in the alanine $\beta$-sheet or 3,10 helices/random coil conformations, we estimated that the ratio of alanine in $\beta$-sheets: Alanine in 3,10helices/random coil is 1:7 in A. keyserlingi silk and 7:1 in N. plumipes silk and 2:1 in L. hasselti silk. Thus, while the amino acid compositions suggested that all of the spiders produced dragline silk comprising of primarily MaSp1 in May, ssNMR revealed that the secondary structures of the proteins within each species' dragline silk differed profoundly.

While L. hasselti dragline silk was structurally more similar to N. plumipes' silk than A. keyserlingi's silk, there was more structural variation between individual fibers in this species compared to the other two species (Figure S2). This may be because there were considerably high signal-to-noise ratios in the resonances attained for the L. hasselti silks because of their exceptional thinness $(<2 \mu \mathrm{m})$. On the other hand spinning conditions within the glands of individual L. hasselti may have induced a wider array of structural variations among the individual dragline silks, or the presence of AcSp1 in L. hasselti dragline silks was variable among individuals.

The secondary structures within A. keyserlingi dragline silk resembled those expected for MaSp2 predominant silk, while those within $N$. plumipes and L. hasselti dragline silk more resembled those expected for MaSp1 predominant silk. N. plumipes' dragline silk yielded the narrowest signal at the alanine $\mathrm{C}_{\alpha}$ site (70 ppm), indicating a higher degree of order and crystallinity in their silks compared to A. keyserlingi or L. hasselti silks. Since there were incongruencies between the amino acid compositions revealed by HPLC and the protein secondary structures revealed by ssNMR we concluded that silk spinning processes may have acted to dissociate the protein secondary structures from spidroin expression, or other spidroins may have been incorporated into some of the silks. 


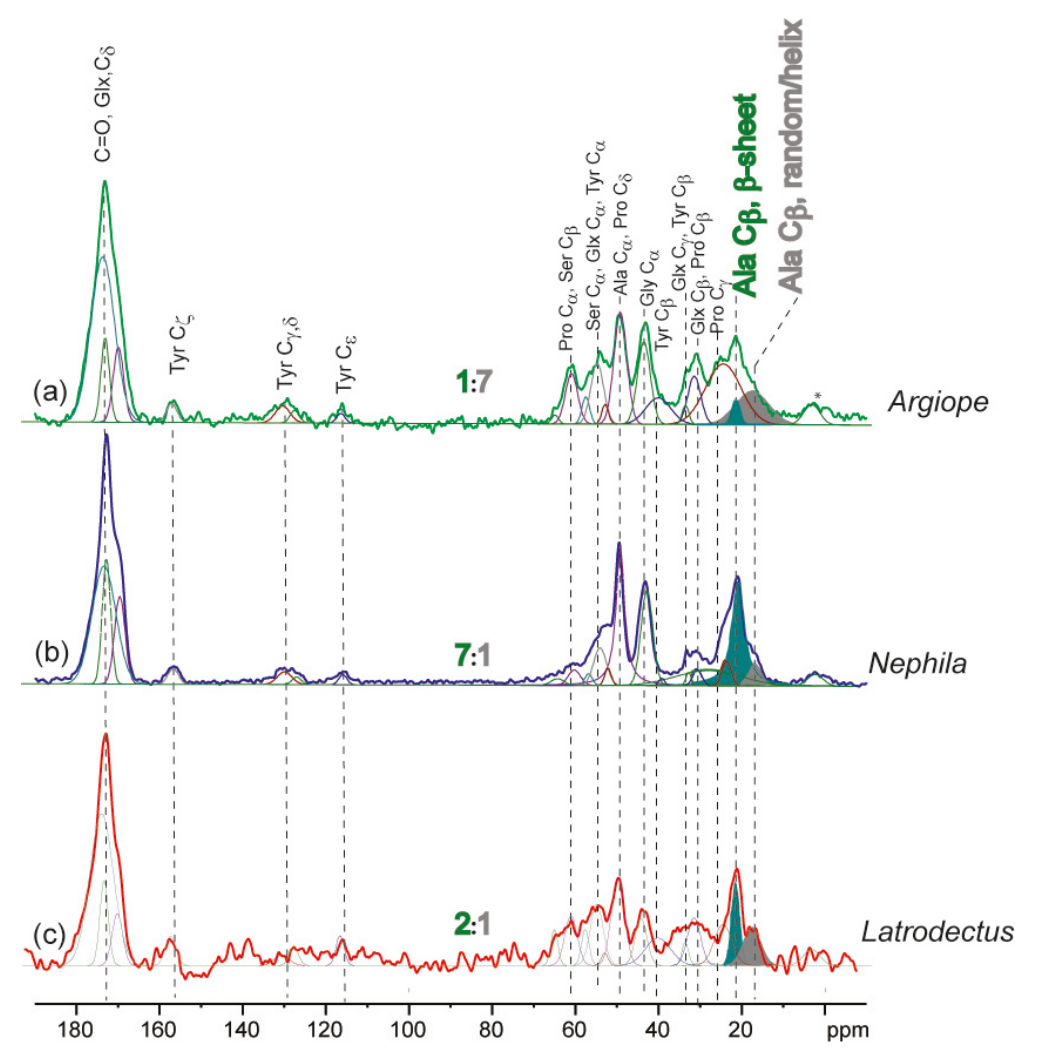

Figure 1. ${ }^{13} \mathrm{C}$ CPMAS ssNMR of silk from individual: (a) Argiope keyserlingi (Argiope); (b) Nephila plumipes (Nephila); and (c) Latrodectus hasselti (Latrodectus). The spectral peaks shaded green represent poly-alanine $\beta$-sheets, while those shaded grey represent poly-alanine 3,10 helices/random coils. Accordingly, the spectra show that there are differences in the ratios of alanine in $\beta$-sheets: alanine in 3,10helices/random coil between A. keyserlingi (1:7), N. plumipes (7:1) and L. hasselti (2:1) silks. Spectra of individual spiders within each species are shown in the Supplementary Materials (Figure S1).

\subsection{Influences Affecting Mechanical Properties}

Representative stress-strain curves for three individual L. hasselti, A. keyseringi and N. plumipes silks are shown in the Supplementary Materials (Figure S3). One feature of the curves is what appears to be slippage of the fibers at the early stages of extension. We expect that this was a by-product of the low resolution of measurements of our testing machine, which we found to show high variability when measuring some exceptionally fine fibers. Our procedures, nevertheless, were consistent for all of the silks analyzed and the results were detailed enough to make comparisons between species.

We found that the native state silks of each species had significantly greater ultimate strength but were less extensible than their supercontracted silks, indicating that alignment of the crystalline and amorphous region proteins affected the mechanical properties of each species' native silks independent of spidroin expression $[38,51]$. We suggest that studies involving intraspecific comparisons require more precise mechanical testing methods.

The mechanical properties of the dragline silks from all three species differed (Figure 2). These differences reconciled well with our ssNMR structural analysis. For instance, we found N. plumipes silk to have the highest ultimate strength, which can be attributed to the high crystallinity of its silk. On the other hand, A. keyserlingi's silk had the greatest toughness and extensibility, properties that can be attributed to its low crystallinity and greater distribution of alanine toward 3,10 helices/random coils rather than $\beta$-sheets. Moreover, despite having similar amino acid compositions to the other two species $A$. keyserlingi silk had the greatest percent shrinkage, which may be attributable to its high proportion of helical/coiled structures, as these structures are 
considered more amenable to extension under tension compared to the crystalline structures $[45,52,53]$. The theoretical premise for this prediction is that the weak hydrogen bonds between the amino acid residues in random coil structures would likely have been accessed more readily by water resulting in loss of alignment in the amorphous region $[12,28,29,54]$.

The amino acid composition of $A$. keyserlingi dragline silk collected in May did not differ from the silk amino acid compositions of the other two species, so spidroin expression does not explain the variations in mechanical properties found between the three species' silks. We therefore deduced that the incongruencies between the amino acid compositions and protein secondary structures and mechanical properties among the three species is evidence of decoupling between silk protein secondary structures and spidroin expression. Glandular processes that might induce decoupling may include the shear forces experienced during the final phase of silk spinning inducing crystalline and amorphous region self-alignment in the spun silk [44-46]. Additional amorphous region alignment may be extenuated at the valve by the influence of friction during drawing $[45,55]$. These actions could explain why the mechanical properties of the silks in all three species varied independent of their spidroin expressions and why A. keyserlingi's dragline silk in May resembled MaSp1 predominant silk in amino acid composition but resembled a MaSp2 predominant silk in secondary structure. An alternative possibility is that additional spidroins, such as AcSp1 [50], were additionally expressed in A. keyserlingi dragline silk, rendering the influence of amino acid composition on mechanical properties inconsistent with that expected if only MaSp1 and MaSp2 were expressed.
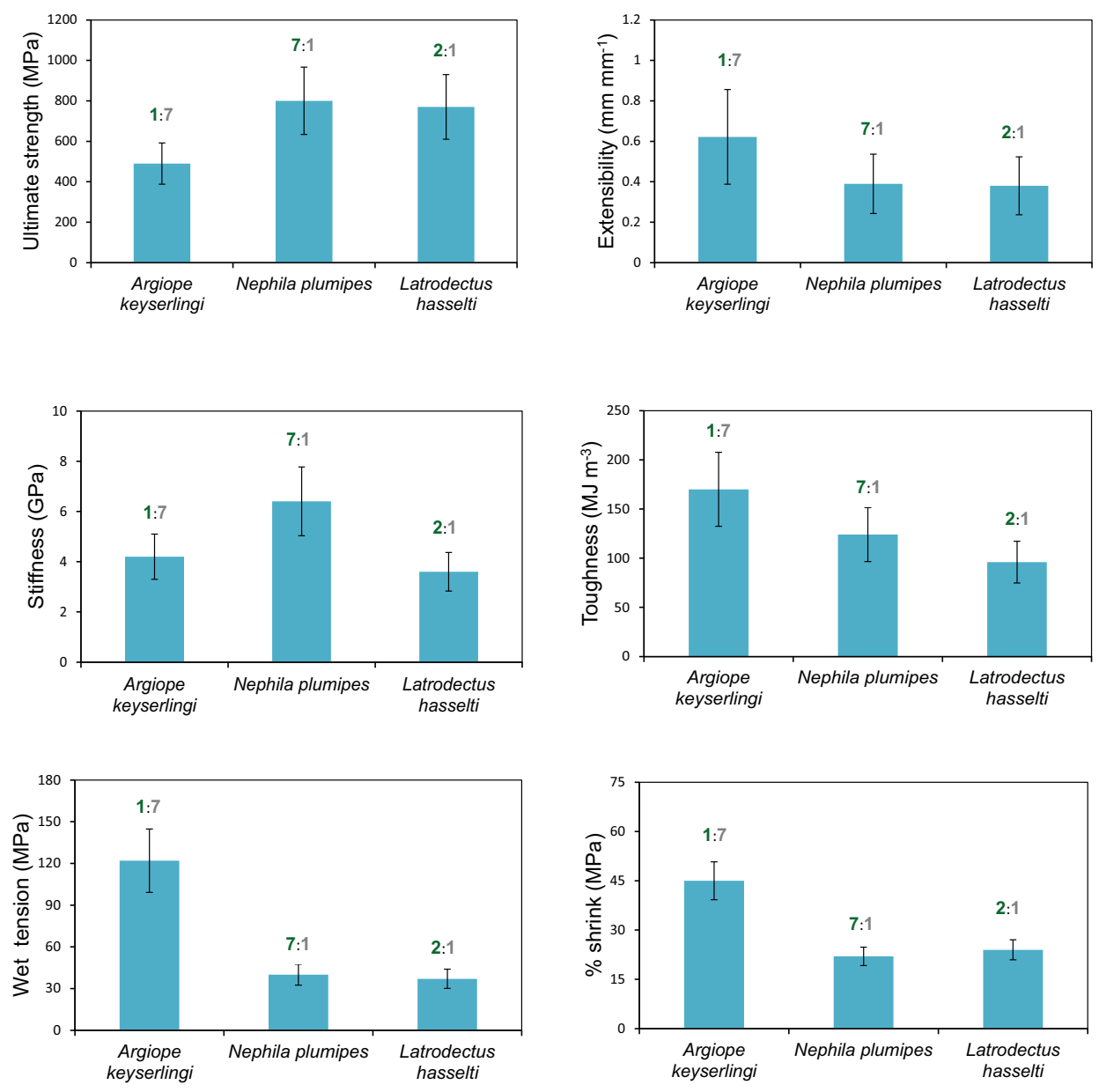

Figure 2. Comparisons of the ultimate strength, extensibility, stiffness and toughness of native silks, and wet tension and percent shrink of supercontracted silks of L. hasselti, A. keyserlingi and N. plumpes dragline silks taken from spiders collected in May. Numbers associated with the respective species' bars show the $\beta$-sheets (green): 3,10 helices/random coil (grey) ratios ascertained by ssNMR (see Figure 1). 


\section{Experimental Section}

\subsection{Spiders and Silk Collecting}

We collected five adult females of three species, Argiope keyserlingi, Nephila plumipes and Latrodectus hasselti, from similar urban habitats in Sydney, New South Wales, Australia, in May 2014, as at this time all three species were active. We collected a further 5 L. hesselti and 5 A. keyserlingi in November 2014 (the time of year when the activities of these two spiders peaked) to determine whether spidroin expression varied in similar spiders at different times of year. N. plumipes was not collected in November as it was not active at this time.

Upon collection of the spiders, we measured their body length to $\pm 0.1 \mathrm{~mm}$ using digital Vernier calipers (Caliper Technologies Corp., Mountain View, CA, USA) and their mass to $\pm 0.001 \mathrm{~g}$ using an electronic balance (Ohaus Corp., Pine Brook, NY, USA) before placing them in $115 \mathrm{~mm}$ (wide) $\times 45 \mathrm{~mm}$ (high) plastic circular containers. The containers had perforated wire mesh lids with a $20 \mathrm{~mm}$ long slit cut into them using a Stanley knife to facilitate feeding with a $50 \mu \mathrm{L}$ micropipette. We fed all of the spiders $20 \mu \mathrm{L}$ (L. hesselti and A. keyserlingi) or $50 \mu \mathrm{L}$ (N. plumipes) of an unlabeled $30 \% w / v$ glucose solution daily over five days (for details of solution preparation see Blamires et al. [31,38]) to standardize the recent diet of all spiders prior to collecting their silk. We reweighed the spiders after the 5 days of feeding and individuals whose mass deviated $>50 \%$ from the mean for the species (one L. hasselti and one N. plumpes collected in May) were discarded.

We anaesthetized each spider using $\mathrm{CO}_{2}$ gas and carefully pulled a single dragline fiber from the spinnerets using tweezers and wrapped it around a glass tube connected to a mechanical spool. The spool was spun at a constant speed $\left(1 \mathrm{~m} \cdot \mathrm{min}^{-1}\right)$ for $\sim 1 \mathrm{~h}$ whereupon $10-15 \mathrm{mg}$ of silk was collected. We estimated that this amount of silk closely represents the complete store of silk from the major ampullate gland for each of these species. All silks were extracted under controlled temperature $\left(\sim 25^{\circ} \mathrm{C}\right)$ and humidity $(\sim 50 \%$ R.H.) in still air, so reeling and the post-spin environment did not influence their subsequent chemical or mechanical properties.

\subsection{High Performance Liquid Chromatography (HPLC)}

We used HPLC to determine amino acid compositions using 1-5 mg of silk collected from the 13 individual spiders ( 4 or 5 individual $\times 3$ species) collected in May and 1-5 mg of silk from the 10 (five L. hasselti and five A. keyserlingi) spiders collected in November. Thus, 25 samples were prepared for HPLC analysis in total.

We weighed all of the silk samples to the nearest $0.001 \mathrm{mg}$ on an electronic balance, before placing them into 100- $\mu \mathrm{L}$ Eppendorf tubes, submerging them in $99 \%$ hexaflouro-isopropanol solvent $(500 \mu \mathrm{L}$ of per mg of silk) and leaving them overnight. After removal of the solvent, the samples were then placed in glass tubes and hydrolyzed in $6 \mathrm{M} \mathrm{HCl}$ for $24 \mathrm{~h}$ in a furnace at $115^{\circ} \mathrm{C}$. The amino acids were separated in a Pico-Tag amino acids column (Waters, Milford CA, USA) and we determined the mole percentages of glutamine, serine, proline, glycine, and alanine (as these amino acids represent $>80 \%$ of the total amino acids of dragline silks in most spiders [56]).

We used a single-factor multivariate analysis of variance (MANOVA) and Fisher's Least Significant Difference post-hoc analysis to compare the mean ( \pm standard errors) mole percentages of glutamine, serine, proline, glycine, and alanine between species when collected in May. We additionally performed between species (L. hasselti versus A. keyserlingi) comparisons of the amino acid mole percentages for silks collected in May and November, as well as within species comparisons of the amino acid mole percentages of the silks collected in November.

\subsection{Solid-State NMR (ssNMR) Spectroscopy}

We used ${ }^{13} \mathrm{C}$ cross-polarization magic-angle spin (CPMAS) solid-state NMR analyses to examine and compare the protein secondary structures of 3 of the L. hasselti, A. keyserlingi and N. plumipes dragline silks collected in May to ascertain whether the amino acid compositions predictably 
represented protein secondary structures. The silks were not enriched with isotopes since metabolic processing of ${ }^{13} \mathrm{C}$ or other isotopes may confound the spectra attained using ${ }^{13} \mathrm{C} C \mathrm{CPMAS}$ ssNMR.

We used 5-10 mg of silk from each spider collected. We performed a pre-assessment using a different set of spiders and found 5-10 mg of unlabeled silk to be adequate to attain reliable NMR spectra. The silk samples were packed in $2.5 \mathrm{~mm}$ zirconia MAS rotors with vespel caps. We were careful not to expose the silks to the atmosphere by immediately packing the silks into airtight containers post extraction, and minimizing the exposure to air when packing the sample holders.

The ssNMR spectra were acquired using a Bruker Avance III NMR spectrometer (Bruker Pty Ltd., Melbourne, Australia), with a 16.4 Tesla superconducting magnet operating at $175 \mathrm{MHz}$ and $700 \mathrm{MHz}$ frequencies for the detection of ${ }^{13} \mathrm{C}$ and ${ }^{1} \mathrm{H}$ isotopes respectively. The $2.5 \mathrm{~mm}$ NMR rotor was spun at $30 \mathrm{kHz}$ MAS in a $2.5 \mathrm{~mm}$ triple resonance probehead. The ${ }^{13} \mathrm{C}$ CPMAS ssNMR spectra were acquired with ${ }^{1} \mathrm{H}$ to ${ }^{13} \mathrm{C}$ cross-polarization with a 2 ms contact time, SPINAL-64 decoupling for ${ }^{1} \mathrm{H}$ decoupling at a field strength of $100 \mathrm{kHz}$, and a recycle delay of $4 \mathrm{~s}$. Then, 16k-64k transients were co-added to reduce the signal-to-noise ratio. The $\mathrm{C}=\mathrm{O}$ peak for pure glycine was set to $176 \mathrm{ppm}$ as an external reference for the ${ }^{13} \mathrm{C}$ chemical shifts [21]. The width of the alanine $C_{\alpha}$ signal $(49.6 \mathrm{ppm})$ provided insights for determining the overall crystallinity of the ordered domains. Under the acquisition conditions assigned (i.e., $30 \mathrm{kHz}$ MAS), suppression of the ${ }^{1} \mathrm{H}-{ }^{13} \mathrm{C}$ dipolar coupling ensured that only signals from rigid domains could have been detected using our technique.

\subsection{Tensile Testing}

Tensile testing was done on a single thread of dragline silk from each of the 15 spiders collected in May to ascertain whether the amino acid compositions or secondary structures explained the mechanical properties of each of the three species' silks. To do this, we connected a revolving headframe to the mechanical spool. We attached a $240 \mathrm{~mm}$ long $\times 40 \mathrm{~mm}$ wide cardboard (for native silk testing) or plastic (for supercontracted silk testing) strip, which had six $30 \mathrm{~mm} \times 30 \mathrm{~mm}$ square holes punched at $10 \mathrm{~mm}$ intervals to the headframe. Double sided sticky tape was stuck onto the cardboard at the border of the holes. A single thread was pulled from the spinnerets of an anaesthetized spider and stuck to one of the pieces of sticky tape. The headframe was rotated once ensuring the silk traversed all of the holes and adhered to the tape. The strip was then removed from the headframe and a drop of water based glue applied to the position where the silk was fastened to the cardboard/plastic. Another frame of equal size with identically positioned holes punched into it was placed on top. The two strips were squeezed together with forceps ensuring that they stuck together. We then cut the strip in the regions between the holes perpendicular to the silk thread, leaving six $30 \mathrm{~mm} \times 30 \mathrm{~mm}$ frames holding a single thread of silk. The above procedure was repeated for each individual from each of the three species (we accordingly collected 30 frames per species: 6 frames $\times 5$ individuals).

We taped one randomly selected frame of silk collected from each spider frame to a microscope slide and examined and photographed it under $1000 \times$ magnification using a polarized light microscope (CKX41, Olympus, Tokyo, Japan) connected to a SPOT Idea $5 \mathrm{Mp}$ digital camera (Spot Imaging Solutions, Sterling Heights, MI, USA). The images were digitized using the program Spot Basic 4.7 (Spot Imaging Solutions, Sterling Heights, MI, USA) and the width of each thread determined as a mean of 12 measurements using the program Image J (NIH, Bethesda, MD, USA). These measurements enabled us to calculate the cross-sectional area of each individual thread used in the ensuing tensile tests.

We performed the following tensile tests under controlled temperature $\left(\sim 25^{\circ} \mathrm{C}\right)$ and humidity ( $\sim 50 \%$ R.H.) in still air within 10 days of silk collection. We performed native state tensile tests on 15 frame-mounted silk samples ( 3 frames each from 5 individuals) per species. To do this, we placed the $30 \mathrm{~mm} \times 30 \mathrm{~mm}$ frames containing a single fiber within the grips of an Instron 5543 tensile testing machine (Instron Machines, Melbourne, Australia) with a resolution to approximately $2 \mu \mathrm{N}$. We ensured that the grips held the silks firmly at the upper and lower frame edges. The left and right sides of the frames were cut away and the silks stretched at a rate of $0.1 \mathrm{~mm} \cdot \mathrm{s}^{-1}$ until the fiber ruptured. 
Stress $(\sigma)$ and strain $(\varepsilon)$ were calculated using equations [57]:

$$
\begin{gathered}
\sigma=\frac{F}{A} \\
\varepsilon=\log _{e} \frac{L}{L_{0}}
\end{gathered}
$$

where $\mathrm{F}$ is the force applied to the specimen measured using the program Bluehill 3.0 (Instron Machines, Melbourne, Australia); A is the cross-sectional area of the thread calculated from the thread diameter assuming a constant thread volume; $\mathrm{L}$ is the instantaneous length of the fiber at a given extension value measured using Bluehill 3.0; and $\mathrm{L}_{0}$ is the original gauge length of the fiber.

Stress versus strain curves were determined for each silk tested by a standard trapezoidal method from which we calculated the following mechanical properties for each specimen: (1) ultimate strength, the stress at rupture; (2) extensibility, the strain at rupture; (3) toughness, the Area under the stress strain curve; and (4) Young's modulus (stiffness), the slope of the stress-strain curve during its initial elastic phase.

We performed supercontracted tensile tests on 8-10 frame-mounted silk samples (two samples each from four to five individuals) per species to calculate the parameters wet tension and percentage shrink. We submersed the fibers within a perspex water bath while the samples were held within the grips of the tensile testing machine without tension applied. We ascertained how much stress was generated by the restrained silks, then the fibers were relaxed while wet and the percentage shrink calculated as the proportional difference between the pre-shrunk $\left(l_{0}\right)$ and post-shrunk $\left(l_{1}\right)$ fiber lengths $[29,51]$. Since immersion in water is expected to interrupt protein alignment in the amorphous region $[11,54]$, these parameters can be presumed to indicate approximately the amount of amorphous chain alignment in the native silks [51]. We then dried the fibers in air at maximum relaxation, upon which they were subjected to the same tensile testing procedures described for native silks.

We compared the ultimate strength, extensibility, toughness and stiffness in the native and supercontracted states, and the wet tension and percentage shrink in the supercontracted state, between species using Multivariate analysis of variance MANOVA. All statistical analyses were performed after checking the variances for heterogeneity using Levene's tests.

\section{Conclusions}

We determined herein dragline silk spidroin expression and structural (i.e., $\beta$-sheet and 3,10 helix alanine conformations and crystallinity) variations between and within three spider species using HPLC and ssNMR respectively. Our HPLC analysis of amino acid composition and ssNMR analysis of protein secondary structures found conflicting results for A. keyserlingi dragline silks collected in May. We tentatively considered this as evidence that silk spinning processes decouple protein secondary structures from spidroin expression. It is nevertheless possible that spidroins other than MaSp1 and MaSp2 also appeared in the dragline silks.

The relatively high proline compositions in A. keyserlingi silks from spiders collected in November indicated that it was likely that MaSp2 was predominantly expressed, while the compositions of their silks from those collected in May indicated that it was likely that MaSp1 was predominantly expressed. In May, glycine and alanine within A. keyserlingi dragline silk were distributed more toward 3,10 helices/random coil than $\beta$-sheets, which contrasted with the conformations within the MaSp1 predominant dragline silks of N. plumipes and L. hasselti. In the latter species' silks, glycine and alanine were distributed more toward $\beta$-sheets. The greater proportion of $\beta$-sheet formations within N. plumipes silk is explainable by their high glycine and alanine compositions, with the majority of the alanine forming $(A)_{n}$ sequences and most of the glycine forming $(G A)_{n}$ sequences that conformed into $\beta$-sheets.

Our tensile tests and HPLC analyses suggested that spidroin expression had little influence on silk mechanical properties. ssNMR, on the other hand, showed that L. hasselti and N. plumipes dragline silks 
had greater alanine $\beta$-sheet conformations and crystallinity than did that of $A$. keyserlingi. The greater helical conformations in A. keyserlingi dragline silks explained its extensibility. Our finding that alanine compositions did not differ between species while $\beta$-sheet conformations differed significantly suggested that "on-the-fly" repositioning of alanine during spinning may be a mechanism for inducing protein secondary structural variations, but this needs verification.

We showed here that while amino acid compositions varied over time in different spiders, decoupling of protein secondary structures from spidroin expression could ensure that functionally effective dragline silks are consistently produced. Our findings improve our understanding of the biological processes that induce dragline silk to vary in chemical, structural and mechanical properties across environments. Such understanding is important if spider dragline silk is to be successfully synthesized commercially.

Supplementary Materials: Supplementary materials can be found at www.mdpi.com/1422-0067/17/8/1294/s1.

Acknowledgments: Research was supported by an Australian Research Council (Discovery Early Career Researcher Award DE140101281) grant to Sean J. Blamires and National Science Council, Taiwan, grants (NSC-102-2311-B-029-001-MY3 and NSC-102-2811-B-029-001) to I-Min Tso and Sean J. Blamires.

Author Contributions: Sean J. Blamires, Michael M. Kasumovic and Aditya Rawal conceived and designed the experiments. Sean J. Blamires collected, fed and silked the spiders. I-Min Tso performed HPLC. Sean J. Blamires and Penny J. Martens conducted the mechanical testing and analyses. James M. Hook and Aditya Rawal performed the NMR experiments and analyzed the spectra. All authors were involved in the preparation of the manuscript.

Conflicts of Interest: The authors declare no conflict of interest.

\section{References}

1. Heim, M.; Keerl, D.; Scheibel, T. Spider silk: From soluble protein to extraordinary fiber. Angew. Chem. Int. Ed. 2009, 48, 3584-3596. [CrossRef] [PubMed]

2. Van Krevelen, D.W. Properties of Polymers: Their Correlation with Chemical Structure, Their Numerical Estimation and Predictions from Additive Group Contributions; Elsevier: Amsterdam, The Netherlands, 2009.

3. Parkhe, A.D.; Seeley, S.K.; Gardner, A.; Thompson, L.; Lewis, R.V. Structural studies of spider silk proteins in the fiber. J. Mol. Recog. 1997, 10, 1-6. [CrossRef]

4. Erdogan, H.; Apaydin, M.S. Incorporating amino acid typing into nuclear magnetic resonance protein structure-based assignments. Proteom. Bioinform. 2012, 5, 116-121. [CrossRef]

5. Fratzl, P.; Jacob, H.F.; Rimmerthaler, S.; Roschger, P.; Klaushofer, K. Position resolved small angle X-ray scattering of complex biological materials. J. Appl. Crystal. 1997, 30, 765-769. [CrossRef]

6. Ene, R.; Papadopoulos, P.; Kramer, F. Combined structural model of spider dragline silk. Soft Matter 2009, 5 , 4568-4574. [CrossRef]

7. Rathore, O.; Sogah, D.Y. Nanostructure formation through $\beta$-sheet self-assembly in silk-based materials. Macromolecules 2001, 34, 1477-1486. [CrossRef]

8. Bovey, F.A.; Miran, P.A. NMR of Polymers; Academic Press: San Diego, CA, USA, 1996.

9. An, B.; Hinman, M.; Holland, G.P.; Yarger, J.L.; Lewis, R.V. Inducing $\beta$-Sheets formation in synthetic spider silk fibers by aqueous post-spin stretching. Biomacromolecules 2011, 12, 2375-2381. [CrossRef] [PubMed]

10. Shi, X.; Yarger, J.L.; Holland, G.P. Elucidating proline dynamics in spider dragline silk fibre using ${ }^{2} \mathrm{H}-{ }^{13} \mathrm{C}$ HETCOR MAS NMR. Chem. Commun. 2014, 50, 4856-4859. [CrossRef] [PubMed]

11. Yang, Z.; Liivak, O.; Seidel, A.; LaVerde, G.; Zax, D.B.; Jelinski, L.W. Supercontraction and backbone dynamics in spider silk: ${ }^{13} \mathrm{C}$ and ${ }^{2} \mathrm{H}$ NMR Studies. J. Am. Chem. Soc. 2000, 122, 9019-9025. [CrossRef]

12. Li, X.; Eles, P.T.; Michal, C.A. Water permeability of spider dragline silk. Biomacromolecules 2009, 10, 1270-1275. [CrossRef] [PubMed]

13. Creager, M.S.; Jenkins, J.E.; Thagard-Yeaman, L.A.; Brooks, A.E.; Jones, J.A.; Lewis, R.V.; Holland, G.P.; Yarger, J.L. Solid-state NMR comparison of various spiders' dragline silk fiber. Biomacromolecules 2010, 11, 2039-2043. [CrossRef] [PubMed]

14. Jenkins, J.E.; Creager, M.S.; Lewis, R.V.; Holland, G.P.; Yarger, J.L. Quantitative correlation between the protein primary sequences and secondary structures in spider dragline silks. Biomacromolecules 2010, 11, 192-200. [CrossRef] [PubMed] 
15. Xu, D.; Yarger, J.L.; Holland, G.P. Exploring the backbone dynamics of native spider silk proteins in black widow silk glands with solution-state NMR spectroscopy. Polymer 2014, 55, 3879-3885. [CrossRef]

16. Shi, X.; Holland, G.P.; Yarger, J.L. Molecular dynamics of spider dragline silk fiber by $2 \mathrm{H}$ MAS NMR. Biomacromolecules 2015, 16, 852-859. [CrossRef] [PubMed]

17. Izdebski, T.; Akhenblit, P.; Jenkins, J.E.; Yarger, J.L.; Holland, G.P. Structure and dynamics of aromatic residues in spider silk: 2D carbon correlation NMR of dragline fibers. Biomacromolecules 2010, 11, 168-174. [CrossRef] [PubMed]

18. Rauscher, S.; Baud, S.; Miao, M.; Keeley, F.W.; Pomes, R. Proline and glycine control protein self-organization into elastomeric or amyloid fibrils. Structure 2006, 14, 1667-1676. [CrossRef] [PubMed]

19. Holland, G.P.; Yarger, J.L.; Lewis, R.V. WISE NMR characterization of nanoscale heterogeneity and mobility in supercontracted Nephila clavipes spider dragline silk. J. Am. Chem. Soc. 2004, 126, 5867-5872. [CrossRef] [PubMed]

20. Addison, J.B.; Ashton, N.N.; Weber, W.S.; Stewart, R.J.; Holland, G.P.; Yarger, J.L. $\beta$-Sheet nanocrystalline domains formed from phosphorylated serine-rich motifs in caddisfly larval silk: A solid state NMR and XRD study. Biomacromolecues 2013, 11, 1140-1148. [CrossRef] [PubMed]

21. Holland, G.P.; Jenkins, J.E.; Creager, M.S.; Lewis, R.V.; Yarger, J.L. Solid-state NMR investigation of major and minor ampullate spider silk in the native and hydrated states. Biomacromolecules 2008, 9, 651-657. [CrossRef] [PubMed]

22. Xu, D.; Shi, X.; Thompson, F.; Weber, W.S.; Mou, Q.; Yarger, J.L. Protein secondary structure of Green Lynx spider dragline silk investigated by solid-state NMR and X-ray diffraction. Int. J. Biol. Macromol. 2015, 81, 171-179. [CrossRef] [PubMed]

23. Jenkins, J.E.; Sampath, S.; Butler, E.; Kim, J.; Henning, R.W.; Holland, G.P.; Yarger, J.L. Characterizing the secondary protein structure of black widow dragline silk using solid-state NMR and X-ray diffraction. Biomacromolecules 2013, 14, 3472-3483. [CrossRef] [PubMed]

24. Shen, Y.; Johnson, M.A.; Martin, D.C. Microstructural characterization of Bombyx mori silk fibers. Macromolecules 1998, 31, 8857-8864. [CrossRef]

25. Asakura, T.; Yang, M.; Kawase, T.; Nakazawa, Y. ${ }^{13} \mathrm{C}$ solid-state NMR Study of structural heterogeneity in peptides containing both polyalanine and repeated GGA sequences as a local structural model of Nephila clavipes dragline silk (Spidroin 1). Macromolecules 2005, 38, 3356-3363. [CrossRef]

26. Craig, C.L.; Riekel, C. Comparative architecture of silks, fibrous proteins and their encoding genes in insects and spiders. Comp. Biochem. Physiol. B 2002, 133, 493-507. [CrossRef]

27. Savage, K.N.; Gosline, J.M. The role of proline in the elastic mechanism of hydrated spider silks. J. Exp. Biol. 2008, 211, 1948-1957. [CrossRef] [PubMed]

28. Liu, Y.; Shao, Z.Z.; Vollrath, F. Elasticity of spider silks. Biomacromolecules 2008, 9, 1782-1786. [CrossRef] [PubMed]

29. Boutry, C.; Blackledge, T.A. Evolution of supercontraction in spider silk: Structure-function relationship from tarantulas to orb-weavers. J. Exp. Biol. 2010, 213, 3505-3514. [CrossRef] [PubMed]

30. Van Beek, J.D.; Hess, S.; Vollrath, F.; Meier, B.H. The molecular structure of spider dragline silk: Folding and orientation of the protein backbone. Proc. Nat. Acad. Sci. USA 2002, 99, 10266-10271. [CrossRef] [PubMed]

31. Blamires, S.J.; Wu, C.L.; Tso, I.M. Variation in protein intake induces variation in spider silk expression. PLoS ONE 2012, 7, e31626. [CrossRef] [PubMed]

32. Blamires, S.J.; Wu, C.L.; Blackledge, T.A.; Tso, I.M. Environmentally induced post-spin property changes in spider silks: Influences of web type, spidroin composition and ecology. Biol. J. Linn. Soc. 2012, 106, 580-588. [CrossRef]

33. Blamires, S.J.; Wu, C.L.; Blackledge, T.A.; Tso, I.M. Post-secretion processing influences spider silk performance. J. R. Soc. Interface 2012, 9, 2479-2487. [CrossRef] [PubMed]

34. Craig, C.L.; Hsu, M.; Kaplan, D.L.; Pierce, M.E. A comparison of the composition of silk proteins produced by spiders and insects. Int. J. Biol. Macromol. 1999, 24, 109-118. [CrossRef]

35. Guehrs, K.H.; Schlott, B.; Grosse, F.; Weisshart, K. Environmental conditions impinge on dragline silk prtotein composition. Insect Mol. Biol. 2008, 17, 553-564. [CrossRef] [PubMed]

36. Craig, C.L.; Riekel, C.; Herberstein, M.E.; Weber, R.S.; Kaplan, D.; Pierce, N.E. Evidence for diet effects on the composition of silk proteins produced by spiders. Mol. Biol. Evol. 2000, 17, 1904-1913. [CrossRef] [PubMed] 
37. Tso, I.M.; Wu, H.C.; Hwang, I.R. Giant wood spider Nephila pilipes alters silk protein in response to prey variation. J. Exp. Biol. 2005, 208, 1053-1061. [CrossRef] [PubMed]

38. Blamires, S.J.; Liao, C.P.; Chang, C.K.; Chuang, Y.C.; Wu, C.L.; Blackledge, T.A.; Sheu, H.S.; Tso, I.M. Mechanical performance of spider silk is robust to nutrient-mediated changes in protein composition. Biomacromolecules 2015, 16, 1218-1225. [CrossRef] [PubMed]

39. Marhabaie, M.; Leeper, T.C.; Blackledge, T.A. Protein composition correlates with the mechanical properties of spider (Argiope trifasciata) dragline silk. Biomacromolecules 2014, 15, 20-29. [CrossRef] [PubMed]

40. Liao, C.P.; Chi, K.; Tso, I.M. The effects of wind on trap structural and material properties of a sit-and-wait predator. Behav. Ecol. 2009, 20, 1194-1203. [CrossRef]

41. Dicko, C.; Vollrath, F.; Kennedy, J.M. Spider silk protein folding is controlled by changing $\mathrm{pH}$. Biomacromolecules 2004, 5, 704-710. [CrossRef] [PubMed]

42. Hedhammer, M.; Rising, A.; Grip, S.; Saenz Martinez, A.; Nordling, K.; Casals, C.; Stark, M.; Johansson, J. Structural properties of recombinant nonrepetitive and repetitive parts of major ampullate spidroin 1 from Euprosthenops australis: Implications for fiber formation. Biochemistry 2008, 47, 3407-3417. [CrossRef] [PubMed]

43. Knight, D.P.; Knight, M.M.; Vollrath, F. Beta transitions and stress-induced phase separation in the spinning of spider dragline silk. Int. J. Biol. Macromol. 2000, 27, 205-210. [CrossRef]

44. Vollrath, F.; Knight, D.P. Liquid crystalline spinning of spider silk. Nature 2001, 410, 541-548. [CrossRef] [PubMed]

45. Lefevre, T.; Paquet-Mercier, F.; Rioux-Dube, J.F.; Pezolet, M. Structure of silk by Raman spectromicroscopy: From the spinning glands to the fibers. Biopolymers 2011, 97, 322-335. [CrossRef] [PubMed]

46. Giesa, T.; Perry, C.C.; Buehler, M.J. Secondary structure and critical stress for a model of spider silk assembly. Biomacromolecules 2016, 17, 427-436. [CrossRef] [PubMed]

47. Ayoub, N.A.; Garb, J.E.; Tinghitella, R.M.; Collin, M.A.; Hayashi, C.Y. Blueprint for a high-performance biomaterial: Full-length spider dragline silk genes. PLoS ONE 2007, 2, e514. [CrossRef] [PubMed]

48. Zhang, Y.; Zhao, A.C.; Sima, Y.H.; Lu, C.; Xiang, X.H.; Nakagaki, M. The molecular structures of major ampullate silk proteins of the wasp spider, Argiope bruennichi: A second blueprint for synthesizing de novo silk. Comp. Biochem. Physiol. B 2013, 164, 151-158. [CrossRef] [PubMed]

49. Work, R.W.; Young, T.C. The amino acid compositions of major ampullate and minor ampullate silks of certain orb-web building spiders (Araneae, Araneidae). J. Arachnol. 1987, 15, 65-80.

50. Chaw, R.C.; Correa-Garhwal, S.M.; Clarke, T.H.; Ayoub, N.A.; Hayashi, C.Y. Proteomic evidence for components of spider silk synthesis from black widow silk glands and fibers. J. Proteome Res. 2015, 14, 4223-4231. [CrossRef] [PubMed]

51. Elices, M.; Plaza, G.R.; Perz-Riguero, J.; Guinea, G.V. The hidden link between supercontraction and mechanical behaviour of spider silks. J. Mech. Behav. Biomed. Mater. 2011, 4, 658-669. [CrossRef] [PubMed]

52. Gosline, J.M.; Denny, M.W.; De Monte, M.E. Spider silk as rubber. Nature 1984, 309, 551-552. [CrossRef]

53. Vollrath, F. Strength and structure of spider's silk. Rev. Mol. Biotechnol. 2000, 74, 67-83. [CrossRef]

54. Perz-Riguero, J.; Elices, M.; Guinea, G.V. Controlled supercontraction tailors the tensile behaviour of spider silk. Polymer 2003, 44, 3733-3736. [CrossRef]

55. Grubb, D.T.; Jelinski, L.W. Fiber morphology of spider silk: The effects of tensile deformation. Macromolecules 1997, 30, 2860-2867. [CrossRef]

56. Lewis, R.V. Bionanotechnology: Proteins to Nanodevices; Renugopalakrishnan, V., Lewis, R.V., Eds.; Springer: Dordrecht, The Netherlands, 2006; pp. 61-78.

57. Meyers, M.A.; Chawla, K.K. Mechanical Behavior of Materials; Cambridge University Press: Cambridge, UK, 2009.

(C) 2016 by the authors; licensee MDPI, Basel, Switzerland. This article is an open access article distributed under the terms and conditions of the Creative Commons Attribution (CC-BY) license (http://creativecommons.org/licenses/by/4.0/). 